\title{
The mussel pump: properties and modelling
}

\author{
C. Barker Jørgensen ${ }^{1}$, Poul S. Larsen ${ }^{2}$, F. Møhlenberg ${ }^{3}$, H. U. Riisgård ${ }^{4}$ \\ ${ }^{1}$ Zoophysiological Laboratory A, August Krogh Institute, Universitetsparken 13, DK-2100 Copenhagen, Denmark \\ ${ }^{2}$ Fluid Mechanics Department, Technical University of Denmark, DK-2800 Lyngby, Denmark \\ ${ }^{3}$ Marine Pollution Laboratory, National Agency of Environmental Protection, Jægersborg Allé 1B, DK-2920 Charlottenlund, \\ Denmark \\ ${ }^{4}$ Biological Institute, Odense University, Campusvej 55, DK-5230 Odense M, Denmark
}

\begin{abstract}
Properties of the bivalve pump were assessed by investigating, in the mussel Mytilus edulis, effects on pump characteristics of reduced valve gape, serotonin stimulation of ciliary activity, as well as spawning. Reduced valve gaping caused a proportional decline both in flow rate at zero back pressure, $\mathrm{V}^{0}$, and in pump pressure at zero flow, $\Delta \mathrm{H}_{12}^{0}\left(=\Delta \mathrm{H}_{\mathrm{p}}^{0}\right.$ l, the coefficient $\mathrm{C}_{12}=\Delta \mathrm{H}_{12}^{0} / \mathrm{V}^{0}$ remaining constant. Enhanced beating rate of lateral cilia, induced by serotonin stimulation, did not affect flow rate or pump pressure. Excessive stimulation that eliminated the laterofrontal cirri from the flow pathway had erratic, non-significant effects. Pump pressure and flow rate varied with the extension of mantle edges and expiratory siphon, as correlated with the valve gape. Retraction of mantle edges and siphon at reduced valve gape results in a reduction in width of the interfilament canals and thus in the distance between opposing bands of lateral cilia. This distance appears to be the main factor in determining pump pressure and flow rate in the mussel and other bivalves. The distance tends to be maximal when mantle edges and siphon are fully extended, as they normally are in undisturbed mussels. It is concluded that the rate of water pumping constitutes an emergent property of the spatial geometry of the interfilament canals and the mantle cavity, rather than a physiologically regulated process. Based partly on the experimental results and partly on theoretical assumptions the pump could

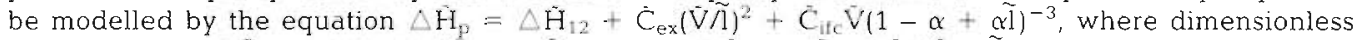

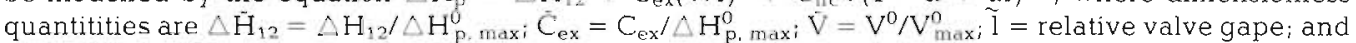
$\tilde{C}_{\mathrm{ifc}}=\mathrm{C}_{\mathrm{ifc}} / \Delta \mathrm{H}_{\mathrm{p}, \max }^{\bar{o}} \cdot \mathrm{C}_{\mathrm{ex}}$ and $\mathrm{C}_{\mathrm{ifc}}$ are coefficients of kinetic energy loss at the exhalant siphon, $\triangle \mathrm{H}_{\mathrm{ex}}$, and of frictional loss in the interfilament canals, $\triangle \mathrm{H}_{1 \mathrm{lc}}$.
\end{abstract}

\section{INTRODUCTION}

The pump and system characteristics of a filter feeding bivalve, Mytilus edulis, pumping water under optimal conditions with fully open valves and extended mantle edges and exhalant siphon were analysed by Jørgensen et al. (1986b). Pumping rate decreases when the gaping of the valves is reduced (Jørgensen 1960, Riisgård \& Randløv 1981), but it remained to be ascertained how pump and system characteristics depend upon the valve gape. Potential factors affecting the pumping rate are (1) the effectiveness of the pump (the bands of lateral cilia along the gill filaments), (2) the frictional resistance to water flow in the canal system, (3) the exit loss (represented by the kinetic energy in the jet current leaving the siphon aperture), and (4) the active resistance of the laterofrontal cirri of the gill. The aims of the present study were to assess the relative importance of these factors and to model the pump.

Valve gape may be actively or passively controlled.
The control is active when exerted by the bivalve itself in shortening the adductor muscle, or passive when the valves are physically prevented from opening fully. Both types of control were studied in order to see whether they differed in their effects on pump and system characteristics.

The bivalve gills filter the water as it enters the interfilament canals and suspended particles are transferred from the through current into the surface currents along the frontal surface of the gill filaments. Discussions of the mechanism of filtration have focused on the role played by the laterofrontal cirri in filter feeding bivalves that do possess such cirri. A crucial element in such discussion is the type and magnitude of the resistance the laterofrontal cirri offer to the passing of water. A previous paper showed that the cirri offered negligible passive, viscous, resistance to water flow, but it was suggested that the cirri may act as an active resistance (Jørgensen et al. 1986b). However, the evidence for an active resistance was incomplete; 
the contributions of the laterofrontal cirri to the pump properties have therefore been examined in further detail.

\section{MATERIAL AND METHODS}

Experimental procedures in analysing pump and system characteristics were the same as those adopted by Famme et al. (1986) and Jørgensen et al. (1986b). In order to determine the relation between passively controlled valve gape and pumping rate, mussels were placed in holders fitted with a screw that controlled the space available for the separation of the valves and thus the valve gape (Jørgensen et al. 1986a, their Fig. 9). Pumping rates were determined from the rates at which mussels cleared the ambient medium of suspended algae (Mohlenberg \& Riisgârd 1979). To correlate pump characteristics with valve gape and area of the aperture of the exhalant siphon, as well as the orientation of the mantle edges surrounding the inhalant opening, mussels were photographed concurrently with measurements of pumping rates and pumping pressures. Photographs were taken normal to the siphon aperture, and valve gape was measured as the distance between the edges of the valves in the middle of the siphon.

Analysis of pump and system characteristics was based on the equation established by Jørgensen et al. (1986b):

$$
\Delta \mathrm{H}_{\mathrm{p}}=\Delta \mathrm{H}_{12}+\Delta \mathrm{H}_{\mathrm{f}}+\Delta \mathrm{H}_{\mathrm{ex}}+\Delta \mathrm{H}_{\mathrm{ff}}
$$

applied on the form

$$
\Delta \mathrm{H}_{\mathrm{p}}=\Delta \mathrm{H}_{12}^{0}-\mathrm{C}_{12} \mathrm{~V}+\mathrm{C}_{\mathrm{f}} \mathrm{V}+\mathrm{C}_{\mathrm{ex}} \mathrm{V}^{2}+\Delta \mathrm{H}_{\mathrm{lf}}
$$

where $\Delta H_{p}=$ pressure rise delivered by the pump, measured e.g. as $\mathrm{mm} \mathrm{H}_{2} \mathrm{O}_{i} \Delta \mathrm{H}_{12}=$ back pressure; $\Delta \mathrm{H}_{\mathrm{f}}$ = frictional resistance in upstream and downstream canals; $\Delta \mathrm{H}_{\mathrm{ex}}=$ exit loss; $\Delta \mathrm{H}_{\mathrm{lf}}=$ presumed active resistance (i.e. a negative quantity) offered by the beating of the laterofrontal cirri against the flow; $\Delta H_{12}^{0}=$ back pressure at zero pumping rate; $V=$ pumping rate $\mathrm{C}_{12}=$ coefficient of the back pressure characteristic, $\Delta \mathrm{H}_{12}^{0} / \mathrm{V}^{0}$, where $\mathrm{V}^{0}=$ flow rate at zero back pressure; $\mathrm{C}_{\mathrm{f}}=$ coefficient of frictional resistance $\mathrm{C}_{\mathrm{ex}}=$ coefficient of the exit loss. For further details, see Jørgensen et al. (1986b).

The importance of the beat frequency of the lateral cilia and the resistance of the laterofrontal cirri was studied by adding serotonin (5-hydroxytryptamine) to the ambient water. Serotonin affects the activity of the ciliary systems of the gill: it stimulates the beat frequency of the lateral cilia and reduces the angle of beat of the laterofrontal cirri (Jorgensen 1975). At a concentration of $10^{-6} M$, serotonin added to the ambient water strongly increases the beat frequency of the lateral cilia. At a concentration of $10^{-5} \mathrm{M}$, serotonin stimulates beat frequency maximally and in addition it reduces the angle of beat of the laterofrontal cirri so that they are removed from the pathway of the currents entering the interfilament canals (Jørgensen 1975, Jorgensen et al. 1986b). When applied at proper concentrations serotonin can therefore be used to study separately the effects of increased beat frequency of the lateral cilia and elimination of an influence of the laterofrontal cirri on pump and system characteristics.

The effects of serotonin were ascertained by quickly opening the mussels and excising fragments of the gill for observation under the microscope. Beat frequency of the lateral cilia was measured stroboscopically The mussels examined were from the same batch as those used to establish back pressure-flow characteristics, to assure that the observed activity also applied during the assessment of the characteristics.

\section{RESULTS AND DISCUSSION}

\section{Relation between passively controlled valve gape, mantle extension, siphon area, and pumping rate}

Reduction in valve gape is accompanied by retraction of mantle edges and siphon, including the reduced area of the siphon aperture. Form and area of the siphon aperture is partly determined by valve gape and partly the result of complex local muscular activity. The muscles in the wall of the siphon can regulate siphon length as well as cross sectional area and shape of the aperture, the shape ranging from circular or oval to slitlike, including combinations of these. Fig. $1 \mathrm{~A}$ to $\mathrm{D}$ shows the relations between passively reduced valve gape and orientation of mantle edges and siphon in an otherwise undisturbed Mytilus edulis. In Fig. 1A the valves are maximally open and mantle edges and exhalant siphon are fully extended. The fringes of the mantle edges surrounding the inhalant opening diverge, as is characteristic of a mussel under optimal conditions, including presence of food suspended in the water In Fig $1 \mathrm{~B}$ the valves are slightly compressed due to restriction in space available, as controlled by turning the screw seen to the left in the photographs with little effect on mantle and siphon. In Fig. $1 \mathrm{C}$ the physical constraint on opening of the valves is substantial. Siphon and mantle edges are extended, presumably as much as is compatible with the reduced gape. Finally, in Fig. 1D the restricted space inhibited the extension of mantle and siphon which hardly reach outside the valves.

The relations between pumping rate $V^{0}$ (at no back pressure) and passively controlled valve gape and area of siphon aperture were determined in 6 mussels and 

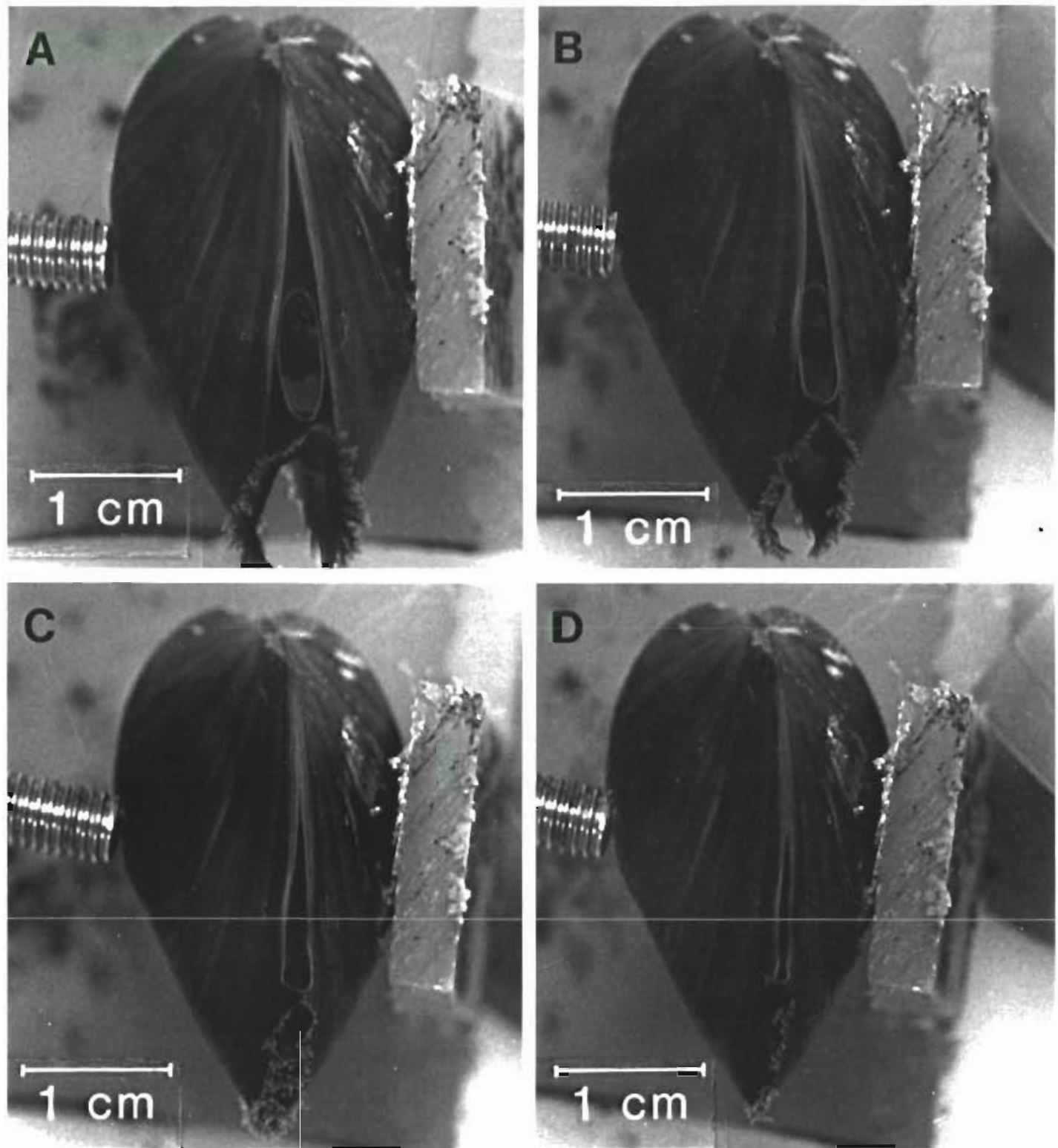

Fig. 1A to D. Mytilus edulis. Photographs showing extension and orientation of mantle edges and exhalant siphon under progressively reduced gaping of the valves, passively controlled by turning the screw

the results are shown in Fig. 2. Obviously, pumping rate is correlated with valve gape but the relations varied individually and they were not well defined. Thus, it seemed important to assess the effects of reduced gaping of the valves simultaneously on both flow rate and pump pressure.

\section{Back pressure-flow characteristic at actively reduced valve gape}

The experimental set-up for passive control of valve gape did not permit simultaneous measurements to be made of flow rate and back pressure. These data therefore had to be obtained in the set-up built for measurements of back pressure-flow characteristics in mussels that spontaneously, i.e. actively, reduced the valve gape during such measurements.

It is relatively easy to establish the relation between an imposed back pressure $\Delta \mathrm{H}_{12}$ and pumping rate $\mathrm{V}$ in a fully open mussel, because the fully open state represents the undisturbed condition. This state is typically stable for periods of time that are sufficiently long for accurate measurements to be made over a range of $\triangle \mathrm{H}_{12}$ values. Reduced valve gape represents a disturbance that only occasionally is maintained long enough 


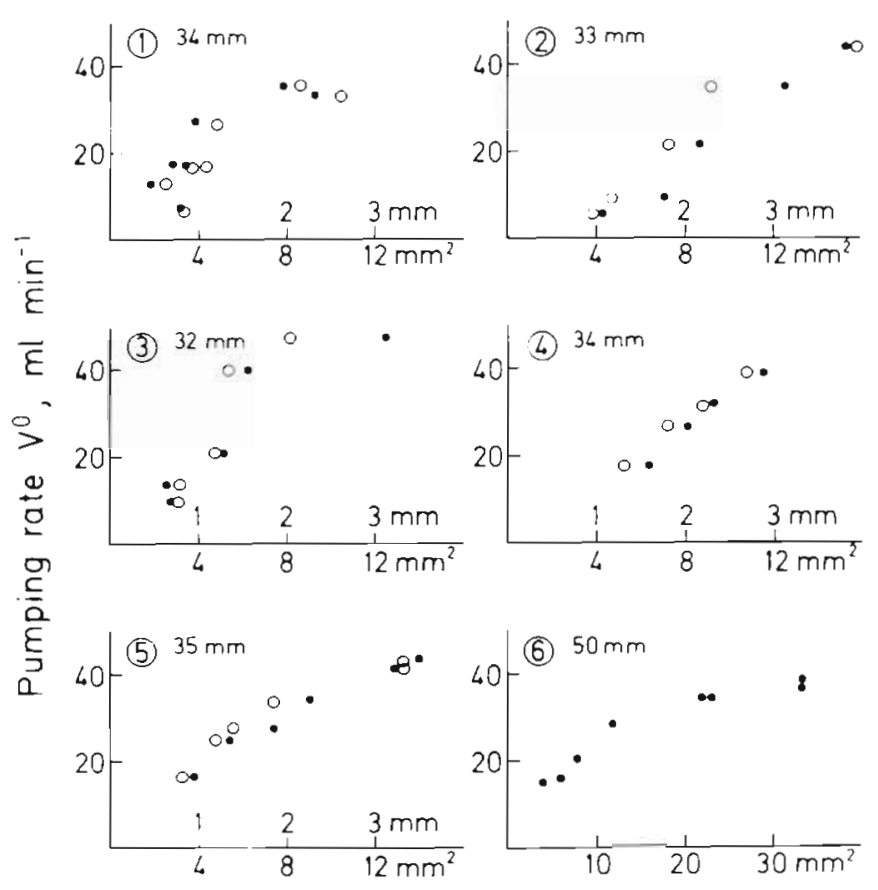

Fig. 2. Mytilus edulis. Pumping rate at zero back pressure (ml $\mathrm{min}^{-1}$ ) versus passively controlled valve gape in $\mathrm{mm}(0)$ and area of siphon aperture in $\mathrm{mm}^{2}(\bullet)$, in 6 individuals ranging in length from 32 to $50 \mathrm{~mm}$

for establishing the back pressure-flow characteristic. Nevertheless, sufficient data were recorded to indicate that at reduced valve gape the attainable back pressure and pumping rate are both reduced and that the coefficient $\mathrm{C}_{12}=\Delta \mathrm{H}_{12}^{0} / \mathrm{V}^{0}$ tended to remain approximately constant. Fig. 3 shows sample data and Table 1 lists results of 3 sets available from unstimulated mussels.

It is fair to conclude that $C_{12}$ (i.e. the slope of lines) did not change significantly at actively reduced valve gape. Moreover, the relations between valve gape for siphon area) and pumping rates at zero back pressure

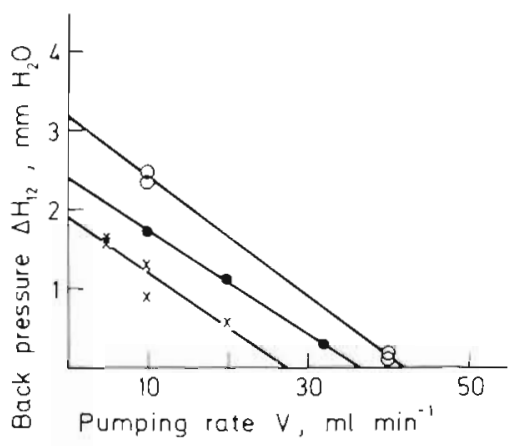

Fig. 3. Mytilus edulis. Effects of actively reduced valve gape on the back pressure-flow characteristic. Valve gape 3.0 to $3.2 \mathrm{~mm}(=) .2 .4$ to $2.6 \mathrm{~mm}(\bullet)$ and 1.4 to $1.5 \mathrm{~mm}(x)$. Abscissa: pumping rate, in $\mathrm{ml} \mathrm{min}^{-1}$ Ordinate: back pressure, in $\mathrm{mm}$ $\mathrm{H}_{2} \mathrm{O}$. Regression lines are shown

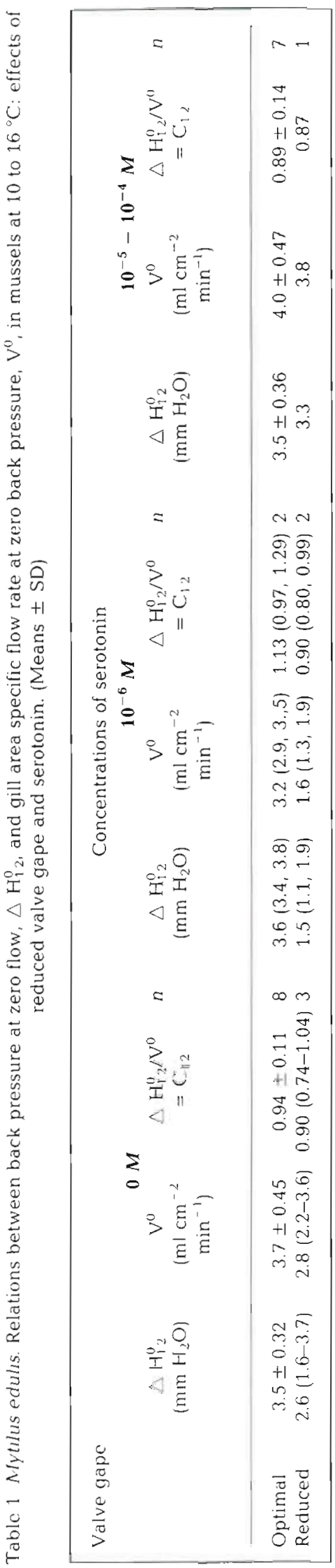


Fig. 4. Mytilus edulis. Pumping rate at zero back pressure ( $\left.\mathrm{ml} \mathrm{min}^{-1}\right)$ versus actively controlled valve gape in $\mathrm{mm}(\mathrm{o})$ or siphon area in $\mathrm{mm}^{2}(\bullet)$

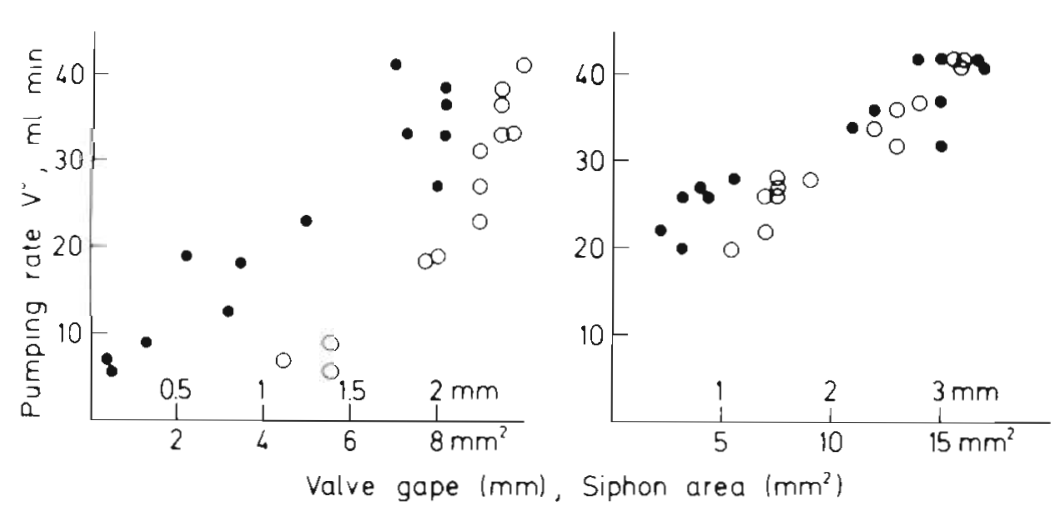

(Fig. 4) were similar to those observed at passively controlled valve gape (Fig. 2), indicating that the causal relationships between valve gape and pumping rate are similar, whether gaping of the valves is actively or passively determined.

As mentioned, reduced gaping of the valves is accompanied by retraction of the mantle edges and exhalant siphon. It is therefore suggested that the declining pump power is related to the retraction of mantle and siphon. This suggestion was supported by casual observations on the relationship between maximum pressure, $\triangle \mathrm{H}_{12}^{0}$, and extension of the mantle edges in a mussel at strongly reduced but constant valve gape. The mussel repeatedly exhibited slight variations in the extension of the mantle edges, the tips of the mantle fringes varying between just reaching or not reaching outside the shell opening. In the first situation the maximum pressure reached 0.4 to $0.6 \mathrm{~mm}$ $\mathrm{H}_{2} \mathrm{O}$, in the second it fell to about $0.2 \mathrm{~mm} \mathrm{H}_{2} \mathrm{O}$.

\section{Effects of serotonin}

Gill fragments. At a concentration of $10^{-6} \mathrm{M}$ serotonin the mean beat frequency ( \pm SD) of the lateral cilia was $22 \pm 2.1 \mathrm{~Hz}(n=4)$, and reached a value of $26 \pm 2.1 \mathrm{~Hz}(n=8)$ at a concentration of $10^{-5} \mathrm{M}$. There was no further increase at a concentration of $10^{-4} \mathrm{M}$. the frequency being $26 \pm 1.1 \mathrm{~Hz}(n=5) ; n$ indicates number of mussels. The values for each mussel are based on 6 to 10 readings from various parts of several gill fragments. The standard deviations of the means of these readings typically amounted to 1 to $2 \mathrm{~Hz}$.

The procedure used did not permit measuring the beat frequency in the gills of unstimulated mussels, because the activity of the lateral cilia vanished soon after excision of a gill fragment. The stimulating effect of $10^{-6} \mathrm{M}$ serotonin therefore cannot be ascertained, but the $22 \mathrm{~Hz}$ measured at this concentration may constitute a doubling of the beat frequence in the unstimulated gill (Jørgensen 1982).
At a concentration of $10^{-6} \mathrm{M}$ serotonin, the laterofrontal cirri continued to beat normally over angles of $90^{\circ}$, from the resting position in the plane of the gill surface, extended over the entrance to the interfilament canals, to the end of the effective stroke normal to the filament surface. At $10^{-5}$ and $10^{-4} M$, the cirri remained immobile at the end of the effective stroke.

Back pressure-flow characteristics. Four back pressure-flow measurements were obtained at a concentration of $10^{-6} \mathrm{M}$ serotonin and 8 at concentrations of $10^{-5}$ or $10^{-4} \mathrm{M}$ (Table 1 ). In only 2 out of the 4 characteristics determined at $10^{-6} \mathrm{M}$ were the mussels fully open, against 7 , of 8 , at $10^{-5}$ or $10^{-4} \mathrm{M}$. In the fully open mussels no statistically significant effects were found of serotonin up to a concentration of $10^{-4} \mathrm{M}$, either on maximal pumping rate $\mathrm{V}^{0}$ or on maximal back pressure $\Delta H_{12}^{0}$. At reduced valve gape the coefficient $\mathrm{C}_{12}$ remained unchanged, as in the unstimulated mussels (Table 1).

Despite the lack of statistical significance, effects of excessive concentrations of serotonin could be observed in 2 out of 4 mussels where we succeeded in determining the back pressure-flow characteristics in the same individual in the fully open state, both unstimulated and serotonin-stimulated (Fig. 5, Table 2). In one of these 4 mussels, serotonin at a concentration of $10^{-5} \mathrm{M}$ exerted a clear effect on both $\mathrm{V}^{0}$ and $\triangle \mathrm{H}_{12}^{0}$ without affecting the coefficient $\mathrm{C}_{12}$ (Fig. $5 \mathrm{~A}$ ). In a second mussel serotonin at a concentration of $10^{-4} \mathrm{M}$ increased $\mathrm{V}^{0}$ and $\triangle \mathrm{H}_{12}^{0}$ slightly (Fig 5B), again without affecting $\mathrm{C}_{12}$. In the last 2 mussels no effect was observed at concentrations of $10^{-5}$ or $10^{-4} \mathrm{M}$ serotonin (Fig. 5C, D).

In order to understand the erratic response to serotonin we shall consider indirect effects on the pump, resulting from stimulation of serotonergically innervated muscles. Serotonergic stimulation is known to inhibit tonic and promote phasic activity in molluscan smooth muscles (Twarog 1954, 1967, York \& Twarog 1973, Aiello et al. 1981). Serotonin added to the ambient water may therefore change the balance 

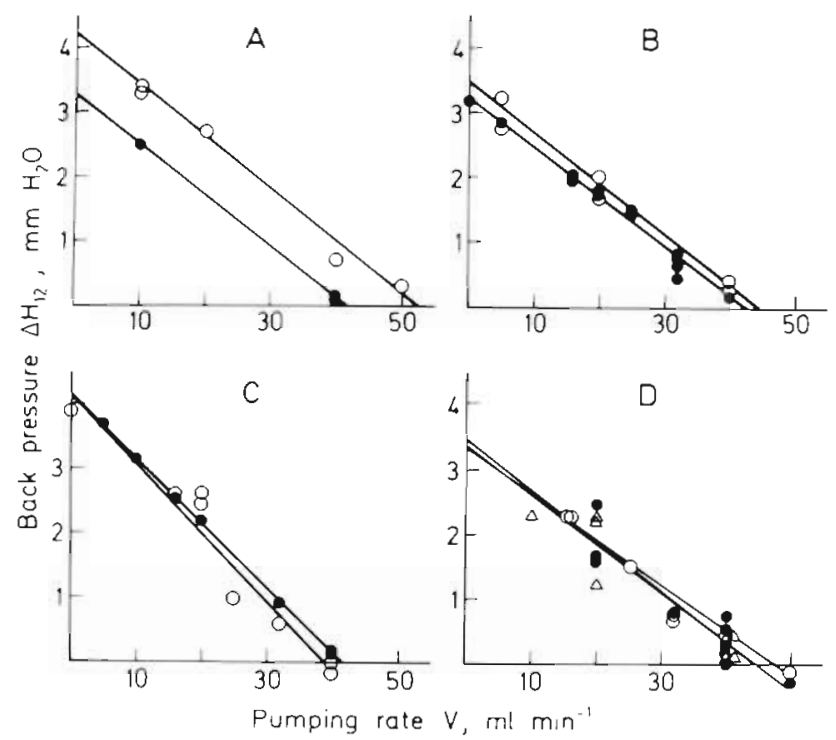

Fig. 5. Mytilus edulis. Effects of serotonin on back pressureflow characteristics in 4 fully open individuals; unstimulated $(\bullet), 10^{-5} \mathrm{M}$ serotonin ( ) $10^{-4} \mathrm{M}$ serotonin $(\Delta)$

between tonic and phasic activities in the adductor muscle that controls valve gape, as well as in the retractor muscles of mantle and siphon.

The effects of serotonin varied with the concentration in the water. At a concentration of $10^{-6} M_{1}$ no effects were observed on valve gape or on extension and orientation of mantle edges and siphon as long as the mussels were left undisturbed. However, when they were placed in the slit of the silicone rubber membrane in the set-up used for recording the relation between back pressure and pumping rate they were more labile in their behaviour, and mostly the valves were less gaping and the mantle and siphon less extended than under the unrestrained condition. Moreover, the exhalant siphon tended to exhibit more or less regular phasic changes in shape and in size of aperture. These effects of restraining the mussels seem to be due to an enhanced excitability to the mechanical stimulj. that arise when the extending mantle obtains contact with the edge of the slit in the membrane. Such contact is crucial to the recording of the relation between pumping rate and pressure difference between the inhalant and exhalant chambers in the set-up, because the contact seals the slit in the membrane and secures that water will pass between the 2 chambers only through the canal systems within the mantle cavity. Presumably, the contact is better tolerated in mussels that are not stimulated by serotonin.

At a concentration of $10^{-5} \mathrm{M}$ serotonin, or higher, the mussels tended to overextend the mantle and siphon, indicating extreme relaxation of the muscles. Moreover, the mussels usually were more tolerant to being placed in the membrane siit than they were at a concentration of $10^{-6} \mathrm{M}$ serotonin in the medium. It was therefore easier to record relations between back pressure and pumping rates in fully open mussels at serotonin concentrations of $10^{-5} M$ than it was at $10^{-6} \mathrm{M}$, as reflected in the number of successful recordings obtained. The enhanced phasic activity, especially of the exhalant siphon, persisted at the higher concentration of serotonin, mostly oscillating around large cross sectional areas of the siphon aperture.

Increasing concentrations of serotonin thus increase relaxation of the muscles, and thereby also valve gape and extension of mantle and siphon. However, excitability persisted even at the highest ambient serotonin concentrations applied $\left(10^{-4} \mathrm{M}\right)$, the mussels responding to mechanical stimulation by closing the valves. And even at this excessive general serotonergic stimulation the integrated function persisted between the muscular systems that regulate valve gape and extension of mantle and siphon.

\section{Valve gape, serotonin stimulation, and pump properties}

Both reduced valve gape and serotonin stimulation thus affected the back pressure-flow characteristic by proportional changes in maximum pump head and pumping rate. The understanding of the pump proper-

Table 2. Mytilus edulis. Regression equations $(y=a+b x)$ describing the back pressure-flow rate characteristics of fully open unstimulated and serolonin-stimulated mussels shown in Fig. 5

\begin{tabular}{|c|c|c|c|c|c|c|}
\hline \multirow[t]{2}{*}{ Mussel } & \multicolumn{3}{|c|}{ Unstimulated } & \multicolumn{3}{|c|}{ Serotonin-stimulated } \\
\hline & $\left(\mathrm{mm} \mathrm{H}_{2} \mathrm{O}\right)$ & b & $r$ & $\frac{\mathrm{a}}{\left(\mathrm{mm} \mathrm{H}_{2} \mathrm{O}\right)}$ & b & r \\
\hline A & 3.27 & -0.079 & -1.00 & 4.18 & -0.080 & -0.99 \\
\hline B & 3.26 & -0.078 & -0.99 & 3.43 & -0.077 & -0.99 \\
\hline C & 4.18 & -0.101 & -1.00 & 4.13 & -0.107 & -0.98 \\
\hline D & 3.44 & -0.077 & -0.95 & 3.30 & -0.070 & $-0.99(10 ; \mathrm{M})$ \\
\hline & & & & 3.32 & -0.075 & $-0.94\left(10^{-4} M\right)$ \\
\hline
\end{tabular}


ties therefore seems to hinge on the elucidation of the relations between valve gape, extension of mantle and siphon and the power of the pump.

Presumably, extension of mantle edges and exhalant siphon is closely coupled to the valve gape, indicating coordinated activity of the muscular systems that control the 2 states. The extension of the mantle and siphon may also be determined by the geometry of the space between the 2 valves, the reduced gaping of the valves limiting extension. The relative importance of coordinated activity of the muscles and pure physical constraint in establishing the relations between valve gape and extension of mantle and siphon remains to be ascertained.

Varying extension of mantle and siphon, secondary to the gaping of the valves, may affect the pump by affecting gill interfilament distances. The muscles that retract mantle and siphon are continuous with muscles running along the bases of the demibranchs at their attachment to the body wall. Retraction of mantle and siphon results in shortening of the demibranch axes and thus of the demibranchs themselves. This shortening is partitioned among the interfilament canals with no change in the width of the filaments. Retraction of mantle and siphon thus concurrently reduces the distance between opposite bands of lateral cilia. This can be observed in preparations where one valve and the underlying mantle has been removed. In such a preparation opposite bands of lateral cilia are typically approaching each other to the extent that the metachronal waves running along the actively beating bands of cilia may interfere during their effective strokes. The effects on the pump of complete retraction of mantle and siphon may be illustrated as follows. In a $32 \mathrm{~mm}$ long, MS222 narcotized mussel with one valve removed the mantle and siphon were retracted and the gill was $24 \mathrm{~mm}$ long. Extension of the mantle edges corresponding to normal in the fully open mussel increased the length of the gill axis by $3 \mathrm{~mm}$. The interfilament canals constitute about half of the gill length, and the distance between opposite bands of lateral cilia during the effective stroke constitutes about $1 / 4$ of the width of the interfilament canal. Thus, the total distance between opposite bands of lateral cilia in the fully open mussel amounted to $1 / 8 \times 27=3.4 \mathrm{~mm}$. The complete shortening of the gill, corresponding to closing of the valves, reduced the distance between the bands of lateral cilia by $3 / 3.4 \times 100=88 \%$, or from 10 to $1.2 \mu \mathrm{m}$. As argued below, it is probably this reduction in width of the interfilament canals, resulting from retraction of mantle and siphon, that is responsible for the concurrent reduction in power and capacity of the gill pump.

In other filter feeding bivalves also, the widths of the interfilament canals vary with the length of the demibranch axes, the length of which is again determined by the degree of extension of mantle edges and siphons (Jørgensen \& Riisgård 1988, and own obs.).

The proportional increase in pump head and pumping rate that might result from excessive serotonin stimulation left no scope for increased flow resulting from diminished frictional resistance with the elimination of the laterofrontal cirri from the entrance to the interfilament canals. It was therefore suggested in a previous paper (Jørgensen et al. 1986b) that the cirri represent an active resistance by beating against the currents entering the interfilament canals. The erratic effects of eliminating the resistance of the laterofrontal cirri, however, speaks against this interpretation. If the laterofrontal cirri did in fact constitute a substantial active resistance the response to serotonin would have been reproducible. The erratic nature of the response is, however, consistent with an interpretation that assumes that serotonin acts indirectly on the pump through its general relaxing effects on the musculature. If such relaxation also affects the length of the gill axes, and thus interfilament distances, a secondary effect might be to enhance the power and capacity of the pump by increasing the width of the interfilament canals. An effect can thus be expected only when the gill axes are not already maximally relaxed, as they mostly seem to be when the mussels process water undisturbedly. The resistance offered by the laterofrontal cirri is thus small, and the term $\triangle H_{\mathrm{If}}$ in Eq. (1) may be ignored.

It is usually assumed that bivalve water pumping is controlled by the activity of the lateral cilia, as is also implicit in the literature that deals with the mechanisms controlling this activity (Aiello 1960, Gosselin 1961, Paparo \& Aiello 1970, Catapane et al. 1978, 1979, 1981, Stefano et al. 1978, Catapane 1982, Paparo 1985). However, both the present results and earlier measurements of pumping rates in mussels stimulated with serotonin disclosed no effects of increased beat frequency of the lateral cilia (Jørgensen 1975), or the effects were erratic (Jørgensen et al. 1986b). The fact that even excessive serotonin stimulation mostly exerts no or insignificant effects on the pump indicates that the gill pump is designed to perform optimally when the adductor muscles and mantle retractor muscles are relaxed, as in undisturbed mussels, and at submaximal frequencies of beating of the lateral cilia.

\section{Pump power, partition on frictional loss and kinetic energy}

The power of the mussel pump is given by the product of operating pressure times flow rate, $P_{p}=$ eg $\triangle H_{p} V$, where $\triangle H_{p}$ is given by Eq. (1). Under normal conditions $\triangle \mathrm{H}_{12}=0$ and $\mathrm{V}=\mathrm{V}^{\mathrm{o}}$.

The power of the pump varied with the valve gape, 
and it may be expressed in terms of a 'standard' pump power, characteristic of the fully open state. Jorgensen et al. (1986b) estimated standard operating pressure to be $1.4 \mathrm{~mm} \mathrm{H}_{2} \mathrm{O}$, of which $\triangle \mathrm{H}_{1 \mathrm{f}}$ constituted $0.4 \mathrm{~mm} \mathrm{H}_{2} \mathrm{O}$. As argued above $\Delta \mathrm{H}_{1 \mathrm{f}}$ is in fact insignificant, and we may therefore adopt $1.0 \mathrm{~mm} \mathrm{H}_{2} \mathrm{O}$ as the operating pressure applying in the fully open state when the pumping rate is maximal.

The energy delivered by the pump is partly dissipated as frictional heat in the canal systems and partly delivered as kinetic energy in the jet current leaving the siphon.

From Eq. (1), at $\Delta \mathrm{H}_{12}$ and $\Delta \mathrm{H}_{\mathrm{lf}}$ equal to zero, we have $\Delta H_{p}=\Delta H_{f}+\Delta H_{e x}$. The pump power is thus given by $\operatorname{gg} \Delta \mathrm{H}_{\mathrm{p}} \mathrm{V}^{0}=\mathrm{g}\left(\mathrm{g} \Delta \mathrm{H}_{\mathrm{f}}+1 / 2 \mathrm{v}^{2}\right) \mathrm{V}^{0}$. When the area of the siphon aperture at the flow rate $V^{0}$ is known we can calculate the velocity in the jet $v$ and thus partition the pump energy between frictional heat loss and kinetic energy in the jet. In 10 fully open mussels the kinetic energy amounted to $15 \pm 7.3$ (SD) percent of the pump power. Because the kinetic energy in the jet is a quadratic function of the flow velocity, the percentage constituted by the kinetic energy varied strongly with $\mathrm{V}$, ranging from $2 \%$ of the pump power at $\mathrm{v}=2 \mathrm{~cm} \mathrm{~s}^{-1}$ to $29 \%$ at $\mathrm{v}=8 \mathrm{~cm} \mathrm{~s}^{-1}$. Mostly, the flow velocities were 5 to $6 \mathrm{~cm} \mathrm{~s}^{-1}$.

\section{Efiect of spawning on pump characteristics and energy partitioning}

The effect of local constriction of the exhalant siphon on partitioning of pump power in mussels with fully gaping valves are difficult to assess, because usually such local constriction is only passing, lasting too short for reliable measurements to be made. However, the spawning state is characterized by prolonged maximal extension of the mantle edges and siphon combined with constriction of the siphon aperture. The pump characteristics were measured in 2 female Mytilus edulis that spawned spontaneously during their stay in the experimental set-up. The results are shown in Table 3 and Fig. 6A, B. Table 3 shows that spawning exerted only minor effects on the pump characteristics. The area of the siphon aperture was significantly restricted during the whole period of spawning that lasted $25 \mathrm{~min}$, and the kinetic energy in the jet increased from about $10 \mu \mathrm{W}$ before spawning to about $20 \mathrm{\mu W}$ with the onset of spawning, or from 10 to $24 \%$ of the total pump power. The second mussel started spawning before the prespawning characteristics could be measured. Initially pumping rate was normal, but it declined as spawning ebbed, with no consistent change in siphon area (Fig. 6A). The kinetic energy in

Table 3. Mytilus edulis. Effect of spawning on pump characteristics. (Means \pm SD)

\begin{tabular}{|c|c|c|c|c|c|c|c|c|c|c|}
\hline \multirow[t]{2}{*}{ Condition } & \multirow[t]{2}{*}{$n$} & \multirow[t]{2}{*}{ Time } & \multirow{2}{*}{$\begin{array}{c}\mathrm{V}^{0} \\
\left(\mathrm{ml} \mathrm{min}^{-1}\right)\end{array}$} & \multirow{2}{*}{$\begin{array}{l}\text { Siphon area } \\
\qquad\left(\mathrm{mm}^{2}\right)\end{array}$} & \multirow{2}{*}{$\begin{array}{c}\text { Valve gape } \\
\text { (mm) }\end{array}$} & \multicolumn{2}{|c|}{ Kinetic energy } & \multicolumn{3}{|c|}{$\Delta H_{12}$ characteristics } \\
\hline & & & & & & & $\% P_{p}$ & $\begin{array}{c}\Delta \mathrm{H}_{12}^{0} \\
\mathrm{a}\end{array}$ & $\begin{array}{c}\Delta \mathrm{H}_{12}^{0} / \mathrm{V}^{0} \\
\mathrm{~b}\end{array}$ & $r$ \\
\hline Prespawning & 9 & $9.45-11.00$ & $41 \pm 3.6$ & $\begin{array}{l}12.9 \pm 1.0 \\
p<0.001\end{array}$ & $3.5 \pm 0.7$ & $\begin{array}{l}9.7 \pm 2.5 \\
p<0.01\end{array}$ & $\begin{array}{l}10 \pm 2.2 \\
p<0.001\end{array}$ & 3.53 & -0.089 & -0.96 \\
\hline Spawning & 7 & $12.00-12.25$ & $38 \pm 3.3$ & $7.8 \pm 0.6$ & $3.5 \pm 0.1$ & $21.2 \pm 6.0$ & $24 \pm 4.8$ & 2.79 & -0.066 & -0.99 \\
\hline
\end{tabular}
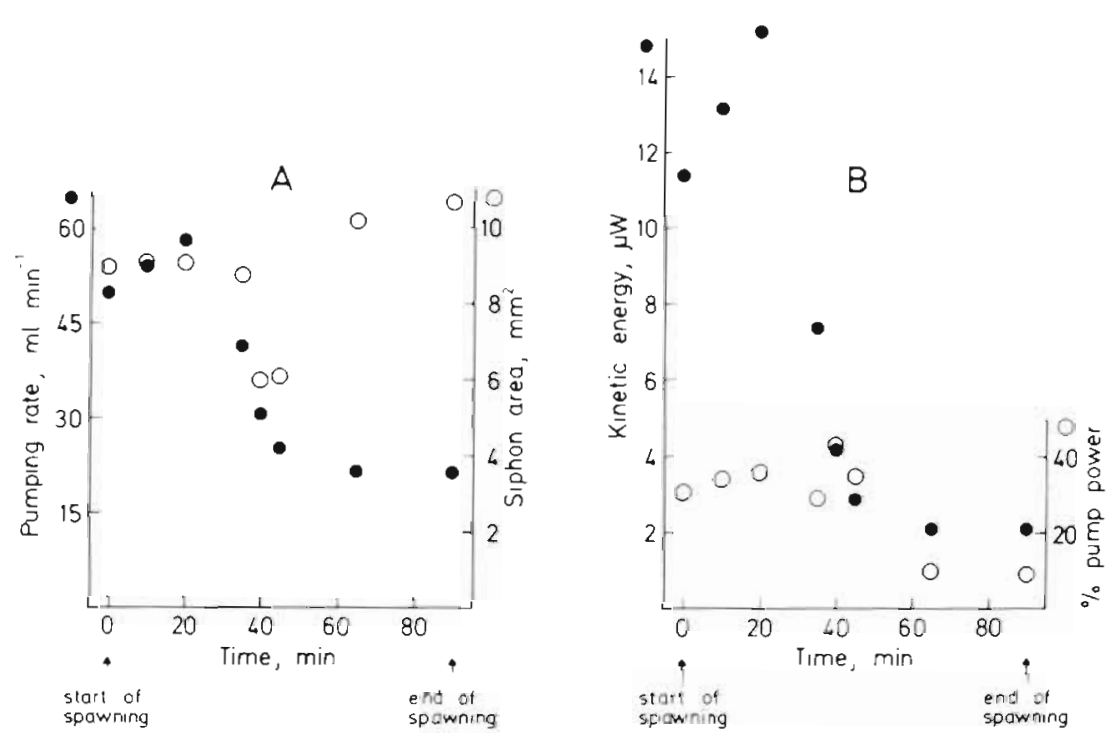

Fig. 6. Mytilus edulis. Effects of spawning in a female on pump properties. Abscissae: time; ordinates: in $A_{\text {, pumping }}$ rate $(\bullet)$ and siphon area (): in $B$, kinetic energy in $\mu W(\bullet)$ and in percent of pump power () 
the jet current approached initially $15 \mu \mathrm{W}$, or more than $30 \%$ of the pump power, to decline to $2 \mu \mathrm{W}$, or $10 \%$ of the pump power (Fig. 6B).

During spawning the mussel gills become leaky, as evidenced by the low rates at which spawners clear the ambient water of algal cells (Newell \& Thompson 1984 , Famme et al. 1986). This leakiness to small particles may result from a reduced angle of beat of the laterofrontal cirri, perhaps induced by serotonin (Jorgensen et al. 1986b). The lack of effect of spawning on the pump is therefore consistent with the insignificance of the term $\triangle H_{1 f}$ in the pump characteristic, as expressed in Eq. (1).

Mytilus edulis shed gametes repeatedly during a spawning period. The most conspicuous feature exhibited at the initiation of spawning is the pronounced relaxation of adductor muscles, mantle edges and exhalant siphon, in combination with a reduction in siphon aperture. Presumably, the functional significance of the constriction of the aperture is to increase the range of distribution of the gametes. For the mussel whose data are recorded in Table 3 the exit velocity of the jet increased from about $5 \mathrm{~cm} \mathrm{~s}^{-1}$ in the prespawning state to about $8 \mathrm{~cm} \mathrm{~s}^{-1}$ when spawning commenced.

\section{Modelling of the pump}

In the following we shall attempt to infer a simplified pump model from the data obtained on the influence of reduce valve gape on volume flow at zero back pressure $V^{0}$ and zero-flow pump pressure rise $\Delta H_{12}^{0}$. As mentioned, reduced valve gape and siphon aperture affected the back pressure-flow characteristic of the mussel pump by proportional changes in $\triangle \mathrm{H}_{12}^{0}$ and $\mathrm{V}^{0}$ (Fig. 3). $V^{0}$ decreased approximately linearly with decreasing valve gape and area of siphon aperture, siphon area being approximately proportional to valve gape (Fig. 2). A plot of $\triangle H_{12}^{0}$ on valve gape, $l_{g}$, obtained from the data shown in Fig. 3, approached linearity (Fig. 7). However, the scatter is considerable.

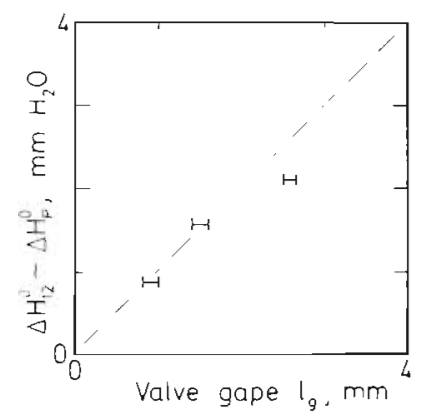

Fig. 7. Mytilus edulis. Relation between valve gape $\mathrm{l}_{g}$ and back pressure at zero flow $\Delta H_{12}^{0} \sim \Delta H_{p}^{0}$ suggesting $\Delta H_{p}^{0} \sim \mathrm{l}_{g}$. Data from Fig. 3
In Eq. (1) the pressure rise over the pump is equated to the sum of all system resistance and imposed back pressure, in effect determining the operating point. In order to characterize the pump we shall model each term of the equation in terms of valve gape and volume flow.

As mentioned, $\triangle H_{1 f}$ is insignificant and may be disregarded. Hence, the maximum pump pressure equals the maximum back pressure, or $\Delta \mathrm{H}_{\mathrm{p}}^{0}=\Delta \mathrm{H}_{12}^{0}$. To first order of approximation, $\Delta \mathrm{H}_{\mathrm{p}}^{0}$ is thus linearly related to valve gape $l_{g}$, or

$$
\triangle \mathrm{H}_{\mathrm{p}}^{0} \simeq \Delta \mathrm{H}_{\mathrm{p}, \max }^{0} \tilde{\mathrm{I}}
$$

where $\tilde{\mathrm{I}}=\mathrm{l}_{\mathrm{g}} / \mathrm{l}_{\mathrm{g}, \text { max }}$ denotes the dimensionless valve gape, being unity at the normal state of fully open valves. Assuming furthermore a linear pump for any valve gape (Jørgensen et al. 1986b) we obtain

$$
\therefore H_{p}=\Delta H_{p}^{0}, \max (\tilde{l}-\widetilde{V}) \text {, }
$$

where $\tilde{V}=V / V_{\text {max }}^{0}$ denotes the dimensionless volume flow; $V_{\max }^{0}=$ zero-pressure volume flow at no resistance or load and at maximum valve gape; $\Delta \mathrm{H}_{\mathrm{p}, \max }^{0}=$ corresponding zero-flow pressure rise.

The first term on the right of Eq. (1), $\Delta H_{12}$, being an externally imposed parameter, needs no modelling.

The second term describes the kinetic energy loss at the exhalant siphon, $\Delta H_{e x}$, which is proportional to the velocity, $v$, squared. The velocity is the ratio of volume flow and area, where the area is assumed to be linear with valve gape, hence

$$
\Delta H_{e x}=v^{2} / 2 g=(V / A)^{2} / 2 g-\left(V / l_{g}\right)^{2}
$$

or

$$
\Delta \mathrm{H}_{\mathrm{ex}}=\mathrm{C}_{\mathrm{ex}}(\tilde{\mathrm{V}} \tilde{\Omega})^{2}
$$

where $\mathrm{C}_{\mathrm{ex}}=\mathrm{a}$ constant. Here, for simplicity, we ignore the explicit contributions from friction $\Delta H_{e s}$, which is small compared with $\mathrm{H}_{\text {ex }}$, as well as the detailed account of siphon wall boundary layers as they tend to augment $\triangle \mathrm{H}_{\mathrm{ex}}$ (Jørgensen et al. 1986b).

Next, all frictional pressure drop is collected in the term describing friction in interfilament canals $\triangle H_{1 f c}$ (the major contribution to the system resistance; Jorgensen et al. 1986b). For developed Poiseuille flow in a parallel-walled channel of length $L$ and width $l_{1 \mathrm{fc}}$ it is $\Delta \mathrm{H}_{\mathrm{lfc}}=12 \mathrm{vL} /\left(\mathrm{gl}_{\mathrm{ifc}}^{2}\right)$ (Jørgensen et al. 1986b), where $v$ denotes kinematic viscosity.

In order to estimate the relation between $\Delta \mathrm{H}_{\text {ifc }}$ and valve gape we must therefore know the relationship between $l_{\text {ifc }}$ and valve gape. Maximum reduction in length of the gill axis, accompanying closing of the valves, results in a reduction in width of the interfilament canals from about 40 to $30 \mu \mathrm{m}$. Hence, a reduction in valve gape from fully open $(\widetilde{l}=1)$ to fully closed $(\widetilde{l}=0)$ is correlated with a reduction in $l_{\text {ifc corresponding to }}$

$$
\mathrm{l}_{\mathrm{ifc}} / \mathrm{l}_{\mathrm{lfc}, \max }=1-\alpha+\alpha \widetilde{\mathrm{l}} ; \alpha=0.25 \text {. }
$$


Employing this model, using $\mathrm{v}=\mathrm{V} / \mathrm{A} \sim \mathrm{V} / \mathrm{l}_{\mathrm{ifc}}$ (since the width of gills remains constant), $L \sim$ constant (since the length of interfilament canals remains constant), we obtain

$$
\Delta H_{i f c}=C_{i f c} \tilde{V}(1-\alpha+\alpha \tilde{l})^{-3} .
$$

Inserting Eqs. (11) to (13) into Eq. (1), ignoring $\Delta H_{\text {lf }}$. and dividing by $\Delta \mathrm{H}_{\mathrm{p} \text {, max }}^{0}$ we obtain

$$
\begin{aligned}
\Delta \tilde{\mathrm{H}}_{\mathrm{p}}=\tilde{\mathrm{I}}-\tilde{\mathrm{V}}= & \Delta \widetilde{\mathrm{H}}_{12}+\widetilde{\mathrm{C}}_{\mathrm{ex}}(\widetilde{\mathrm{V}} / \widetilde{\mathrm{l}})^{2}+ \\
& \widetilde{\mathrm{C}}_{\mathrm{l} \mathrm{fc}} \widetilde{V}(1-\alpha+\alpha \bar{l})^{-3},
\end{aligned}
$$

where dimensionless quantities are $\Delta \widetilde{H}_{12}=\Delta H_{12}$ ' $\Delta \mathrm{H}_{\mathrm{p}, \text { max } i}^{0} \widetilde{\mathrm{C}}_{e x}=\mathrm{C}_{\mathrm{ex}} / \Delta \mathrm{H}_{\mathrm{p}, \text { max } i}^{0} \widetilde{\mathrm{C}}_{\mathrm{itc}}=\mathrm{C}_{\mathrm{ifc}} / \Delta \mathrm{H}_{\mathrm{p}, \max }^{0}$.

Let us now examine solutions to Eq. (14) and compare these to the experimental results. First, for $\Delta \mathrm{H}_{12}=$ 0 . Eq. (14) reduces to a quadratic algebraic equation in the dimensionless zero back-pressure volume flow $\tilde{V}^{0}$ as function of dimensionless valve gape $\tilde{I}$. For representative values we take (for $\widetilde{I}=1) \widetilde{\mathrm{C}}_{\mathrm{ifc}} / \widetilde{\mathrm{C}}_{\mathrm{ex}}=0.44 /(0.14+$ $0.38)=0.85 \simeq 1$ according to Table 3 in Jørgensen et al. (1986b) and $\widetilde{\mathrm{C}}_{\mathrm{ex}}=0.3$ corresponding to $\widetilde{\mathrm{V}}^{0}=1.0 / 1.52=$ 0.66 as read from Fig. 3 in Jørgensen et al. (1986b) for $\Delta \mathrm{H}_{12}=0$. Fig. 8 shows $\tilde{V}^{0}(\tilde{l})$ for $\tilde{\mathrm{C}}_{e x}=0.1,0.3,0.5$ and

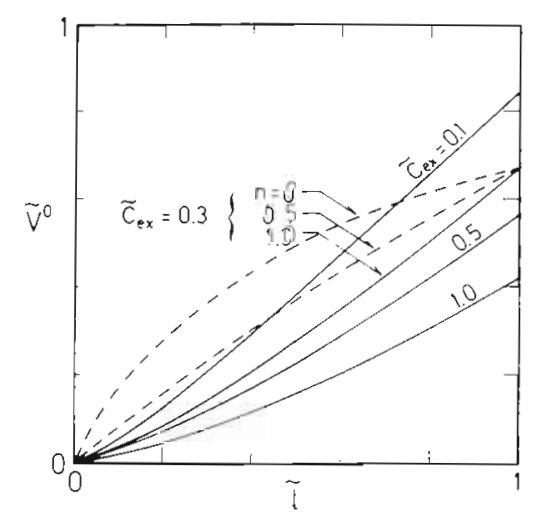

Fig. 8. Mytilus edulis. Relations between dimensionless valve gape $\widetilde{\mathrm{I}}$ and volume flow at zero back pressure $\widetilde{\mathrm{V}}^{\circ}$, from Eq. (15), $\tilde{\mathrm{C}}_{\mathrm{ifc}}=\widetilde{\mathrm{C}}_{\mathrm{ex}}, \alpha=0.25$. Full lines, $n=1.0$, and $\widetilde{\mathrm{C}}_{\mathrm{ex}}=0.1,0.3$, 0.5 and 1.0. Broken lines, $\widetilde{\mathrm{C}}_{\mathrm{ex}}=0.3$ and $n=0,0.5$ and 1.0. For further explanation, see text

1.0. The general behaviour is a nearly linear increase in $\widetilde{V}$ with $\widetilde{I}$. which is consistent with some of the experimental results in Figs. 2 and 4.

However, other data suggest a negative curvature rather than the positive one reflected by the (full line) curves in Fig. 8. It is interesting to note that replacing Eq. (11) by

$$
\Delta H_{p}=\tilde{l}^{n}-\tilde{V}
$$

the curvature of $\widetilde{V}^{0}(\widetilde{l})$ becomes negative, more resembling some of the data in Figs. 2 and 4. This is illustrated by the dashed curves in Fig. 8. It is open to question if the present data are sufficient to suggest more than $n \sim 1$.

Secondly, Eq. (14) may be solved for the backpressure characteristic. For $\widetilde{\mathrm{C}}_{\mathrm{ex}}=0.3$, Fig. 9. shows such results for $\tilde{l}=1,0,0.75$ and 0.6 (corresponding to

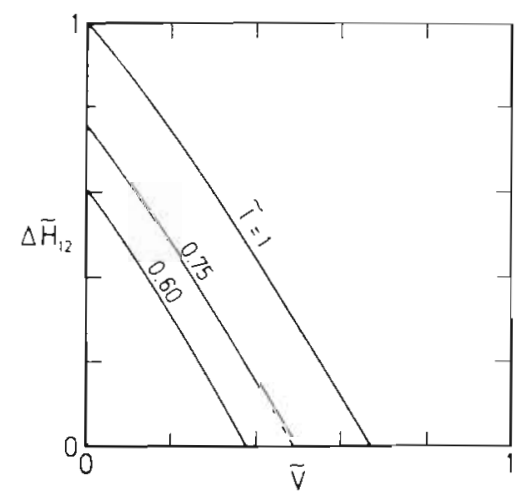

Fig. 9. Mytilus edulis. Niodel back pressure characteristics (dimensionless) from Eq. (14), corresponding to the 3 valve gapes of Fig. 3

the data of Fig. 3). Because $\Delta \tilde{\mathrm{H}}_{\mathrm{ex}}$ is quadratic in $\tilde{V}$ these characteristics are not straight lines but have weak curvatures, particularly for small values of $\tilde{V}$. Clearly, the data of Fig. 3 are insufficient to discern such curvature. Note also that the pump characteristic $\Delta \tilde{H}_{p}=\tilde{I}-\tilde{V}$ for each value of $\tilde{l}$ is simply a straight line at $-45^{\circ}$.

It may thus be concluded that Eq. (14), perhaps modified to

$$
\begin{aligned}
& \Delta \tilde{\mathrm{H}}_{\mathrm{p}}=\tilde{\mathrm{l}}^{\mathrm{n}}-\tilde{\mathrm{V}}=\Delta \tilde{\mathrm{H}}_{12}+\tilde{\mathrm{C}}_{\mathrm{ex}}(\tilde{\mathrm{V}} \tilde{\mathrm{l}})^{2}+ \\
& \widetilde{\mathrm{C}}_{\mathrm{icc}} \tilde{\mathrm{V}}(1-\alpha+\tilde{\alpha \mathrm{l}})^{-3} \text {, }
\end{aligned}
$$

with $\alpha=0.25, \widetilde{\mathrm{C}}_{\mathrm{ex}} \sim \widetilde{\mathrm{C}}_{\mathrm{ffc}} \sim 0.3$, and $0.5<n \leq 1$, is in reasonable agreement with the experimental data shown in Figs. 2, 3 and 4. Eq. (15) is also based on reasonable modelling of frictional and kinetic energy head losses in the mussel. However, the model is so far not based on any specific analysis of the true ciliated pump. It remains to be determined independently, from the structure and the dynamics of the system of lateral cilia, the characteristics of this pump

\section{Ciliary pump models}

The pump consists of the opposing bands of diaplectically beating lateral cilia (Knight-Jones 1954). The bands are about $10 \mu \mathrm{m}$ broad, comprising about 25 cilia. The cilia are thus densely spaced, both across and along the bands. Moreover, the bands are of infinite length compared with the width, extending from base to tip of the filaments, or more than $1 \mathrm{~cm}$ in large mussels. So far there appears to be no theoretical study 
of cilia arranged in narrow bands. Existing theories either consider ciliated surfaces of large extent or they consider single flagella or cilia (see, for example, the review of Brennen \& Winet 1977). Two types of model have been proposed for the hydrodynamics of ciliated surfaces, especially in ciliates: the sublayer model and the envelope model (Blake \& Sleigh 1975, Brennen \& Winet 1977).

The sublayer model is based on the interactions between individual cilia with the surrounding water, and it applies to systems composed of widely spaced cilia, an order of a cilium-length apart. The envelope model assumes that the cilia are closely packed, so that they interact with the surrounding water primarily through the oscillating surface that envelopes the metachronal wave of the ciliary system (Brennen \& Winet 1977). In the lateral bands the cilia are arranged in rows that run obliquely across the band. The rows form angles of about $40^{\circ}$ with the normal across the band (Aiello \& Sleigh 1972). The cilia are spaced $0.2 \mu \mathrm{m}$ apart both across and along the band. During the effective stroke the cilia are fanned out and the interciliary distance increases to about $1 \mu \mathrm{m}$ between the tips of the $15 \mu \mathrm{m}$ long cilia. However, an effective stroke comprises several rows of metachronally beating fanned-out cilia (Aiello \& Sleigh 1972), so that the actual distances between the tips of neighbouring cilia amount to only small fractions of $1 \mu \mathrm{m}$. The currents of water through the interfilament canals pass practically exclusively distal to the tips of the cilia. It therefore sccms that a hydrodynamic theory for the bivalve pump should be based on an envelope model of finite extent (Jørgensen 1982).

In the envelope model of infinite extent the oscillatory motions of the effective material surface produce a rectilinear translation of the fluid tangential to the surface (Brennen \& Winet 1977). In a stationary ciliate, Spirostomum sp., Cheung \& Winet (1975) found that the velocity of the rectified ciliary current attained its highest value at 1 to 1.5 cilia lengths from the ciliated surface. This maximum velocity persisted beyond 2 cilia length before tapering slowly. We do not know at which distance from the surface the current passing a band of lateral cilia attains its maximum velocity. However, consider that the cilia extend about $15 \mu \mathrm{m}$ from the filament walls during the effective stroke, leaving a central gap of about $10 \mu \mathrm{m}$ in a $40 \mu \mathrm{m}$ wide interfilament canal. Obviously, the velocity distributions generated by the opposing bands of cilia must interfere significantly. In fully open mussels this interference may be positive. Such positive interaction is supported by observations that - whereas water currents produced by maximally activated single bands of lateral cilia amount to only $1 \mathrm{~mm} \mathrm{~s}^{-1}$ (Sleigh \& Aiello 1972) or 2 to $3 \mathrm{~mm} \mathrm{~s}^{-1}$ (Jørgensen 1982) - the mean interfila- ment currents at the level of the lateral cilia in intact fully open mussels can be estimated to be about $6 \mathrm{~mm}$ $\mathrm{s}^{-1}$ (Jorgensen 1982).

Presumably, interference becomes negative with decreasing width of the interfilament canals, resulting from reduced valve gape. It is to be expected that the pump characteristic will change, yielding a smaller pressure rise and smaller volume flow, as also inferred in the foregoing section. It is not obvious, however, that the slope of the pump characteristic, and hence largely that of the back pressure characteristic, should remain nearly unchanged. To predict such changes requires a detailed hydrodynamic analysis, which has not yet been attempted.

\section{CONCLUSIONS}

The maximum capacity of the pump in filter-feeding bivalves can be exploited only in fully open individuals with extended mantle edges and siphons, that is, the behaviour adopted by undisturbed animals in the presence of seston, including food particles, suspended in the ambient water. Rates of water processing decline concurrently with the reduction in width of the interfilament canals, being a secondary result of reduced valve gape, retraction of mantle edges and siphons, and shortening of the length of the demibranch axes. Excessive extension of mantle edges and siphons, following excessive relaxation of the musculature-e.g. under spawning or artificial induction via serotonin stimulation - does not, or only moderately, enhance water pumping. It is thus indicated that the pump is designed to obtain the largest favourable hydrodynamic effect of interaction between beating bands of cilia when the animal is fully open. Presumably, this pump potential, reflected in the maximum flow rate, constitutes an evolutionary adaptation to prevailing food concentrations in the environment.

The ill-defined relations between valve gape and water pumping indicate a loose coupling only between the width of the interfilament canals and the muscular activity that controls valve gape and extension of manthe edges and siphons. Reduced pumping rate with decreasing valve gape, therefore, does not appear to be a mechanism in controlling water processing and thus feeding. Rather, reduction in pumping rate is a secondary effect of the mussel's response to suboptimal or adverse environmental conditions.

The fact that water pumping does not necessarily increase with increased beating rate of the lateral cilia supports the conception of an optimised maximum pump capacity. It also indicates that, at least above a certain value, the rate of ciliary beating is not a mechanism in the control of water processing. 
The absence of control of rates of water processing as a means in the control of feeding rates in filter feeding bivalves is comparable with the lack of a physiological relationship between pumping rate and rate of oxygen consumption (Jørgensen et al. 1986a). Presumably, the rate of water pumping constitutes an emergent property of the spatial geometry of the interfilament canals and the mantle cavity.

Acknowledgement. This work was supported by a grant from the Carlsberg Foundation to one of the authors (C. B. J.).

\section{LITERATURE CITED}

Aiello, E. (1960). Factors affecting ciliary activity on the gill of the mussel Mytilus edulis. Physiol. Zool. 33: 120-135

Aiello, E., Sleigh, M. A. (1972). The metachronal wave of lateral cilia of Mytilus edulis. J. Cell Biol. 54: 493-506

Aiello, E., Stefano, G., Catapane, E. (1981). Dual innervation of the foot and the control of foot movement by the central nervous system in Mytilus edulis (Bivalvia). Comp. Biochem. Physiol. 69C: 25-30

Blake, J. R., Sleigh, M. A. (1975). Hydromechanical aspects of ciliary propulsion. In: Wu, T Y., Brokaw, C. J., Brennen, C. (eds.) Swimming and flying in nature, Vol. 1. Plenum, New York, p. 185-209

Brennen, C., Winet, H. (1977). Fluid mechanics of propulsion by cilia and flagella. Ann. Rev. Fluid Mech. 9: 339-398

Catapane, E. (1982). The peripheral innervation of the gill of the marine mollusc demonstrated by the aluminium-formaldehyde (ALFA) histofluorescence method. Cell Tissue Res. 225: 449-454

Catapane, E., Stefano, G., Aiello, E. (1978). Pharmacological study of the reciprocal dual innervation of the lateral ciliated gill epithelium by the CNS of Mytilus edulis (Bivalvia). J. exp. Biol. 74: 101-113

Catapane, E., Stefano, G., Aiello, E. (1979). Neurophysiological correlates of the dopaminergic cilio-inhibitory mechanism of Mytilus edulis. J. exp. Biol. 83: 315-323

Catapane, E., Thomas, J., Stefano, G., Paul, D. (1981). Effects of temperature and temperature acclimation on serotonininduced cilio-excitation of the gill of Mytilus edulis. J. therm. Biol. 6: $61-64$

Cheung, A. T. W., Winet, H. (1975). Flow velocity profile over a ciliated surface. In: Wu, I Y, Brokaw, C. J., Brennen, C. (eds.) Swimming and flying in nature, Vol. 2. Plenum, New York, p. 223-234

Famme, P., Riisgård, H. U., Jørgensen, C. B. (1986). On direct measurements of pumping rates in the mussel Mytilus eduhs. Mar. Biol. 92: 323-327

Gosselin, R. (1961). The cilioexcitatory activity of serotonin. J. cell. comp. Physiol. 58: 17-25

Jorgensen, C. B. (1960). Efficiency of particle retention and rate of water transport in undisturbed lamellibranchs. J. Cons. int. Explor Mer 26: 95-116

Jorgensen, C. B. (1975). On gill function in the mussel Mytilus edulis L. Ophelia 13: 187-232

Jørgensen, C. B. (1982). Fluid mechanics of the mussel gill: the lateral cilia. Mar Biol. 70: 275-281

Jørgensen, C. B., Rüsgård, H. U. (1988). Gill pump characteristics of the soft clam Mya arenaria. Mar Biol. (in press)

Jørgensen, C. B., Møhlenberg, F., Sten-Knudsen, O. (1986a). Nature of relation between ventilation and oxygen consumption in filter feeders. Mar. Ecol. Prog. Ser. 29: 73-88

Jørgensen, C. B., Famme, P., Kristensen, H. S., Larsen, P. S., Møhlenberg, F., Riisgård, H. U. (1986b). The bivalve pump. Mar. Ecol. Prog. Ser. 34: 69-77

Knight-Jones, E. W. (1954). Relations between metachronism and direction of beat in Metazoa. Q. J. microsc. Sci. 95: 503-521

Møhlenberg, F., Riisgård, H. U. (1979). Filtration rate, using a new indirect technique, in thirteen species of suspension feeding bivalves. Mar. Biol. 54: 143-148

Newell, R. I. A., Thompson, R. J. (1984). Reduced clearance rates associated with spawning in the mussel, Mytilus edulis (L.) (Bivalvia, Mytilidae). Mar. Biol. Lett. 5: 21-33

Paparo. A. A. (1985). The role of the cerebral and visceral ganglia in ciliary acitvity. Comp. Biochem. Physiol. 81A: $647-651$

Paparo, A., Aiello, E. (1970). Cilio-inhibitory effects of branchial nerve stimulation in the mussel, Mytilus edulis. Comp. Gen. Pharmacol. 1: 241-250

Riisgård, H. U., Randlov, A. (1981). Energy budgets, growth and filtration rates in Mytilus edulis at different algal concentrations. Mar. Biol. 61 227-234

Sleigh, M. A. Aiello, E. (1972). The movement of water by cilia. Acta Protozool. 11. 265-277

Stefano, G., Hiripi, L., Catapane, E. (1978). The effects of short and long term temperature stress on serotonin, dopamine and norepinephrine concentrations in molluscan ganglia. J. therm. Biol. 3: 79-83

Twarog, B. M. (1954). Responses of a molluscan smooth muscle to acetylcholine and 5-hydroxytryptamine. J. cell. comp. Physiol. 44: 141-163

Twarog, B. M. (1967). Factors influencing contraction and catch in Mytilus smooth muscle. J Physiol. 192: 847-856

York, B., Twarog, B. M. (1973). Evidence for the release of serotonin by relaxing nerves in molluscan muscle. Comp. Biochem. Physiol. 44A: 423-430 


\title{
Efficiency of particle retention and filtration rate in 6 species of Northeast American bivalves
}

\author{
Hans Ulrik Riisgård \\ Institute of Biology, Odense University, Campusvej 55, DK-5230 Odense M, Denmark
}

\begin{abstract}
Particle retention efficiency in 6 species of suspension-feeding Northeast American bivalves was determined by simultaneous measurement of clearance of different sized particles. Geukensia demissa, Spisula solidissima, Brachidontes exustus, and Mercenaria mercenaria, which all possess large laterofrontal cirri, completely retained particles above $4 \mu \mathrm{m}$. Below this the retention efficiency gradually decreased to between 35 and $70 \%$ for $2 \mu \mathrm{m}$ particles. Crassostrea virginica, which has small laterofrontal cirri, and Argopecten irradians, which has none, entirely retained particles above 5 to $6 \mu \mathrm{m}$. Below $5 \mu \mathrm{m}$ the retention efficiency gradually decreased to $50 \%$ for $2 \mu \mathrm{m}$ particles in $\mathrm{C}$. virginica while it sharply dropped to $15 \%$ for $2 \mu \mathrm{m}$ particles in A. irradians. At 27 to $29^{\circ} \mathrm{C}$ filtration rates $\left(F, l \mathrm{~h}^{-1}\right)$ as a function of tissue dry weight $(W, g)$ could be described by the allometric equation: $F=$ $a W^{b}$. In $C$. virginica, $G$. demissa and $M$. mercenaria the equations were: $6.79 W^{0.73}, 6.15 W^{083}$ and $1.24 W^{0.80}$, respectively. $B$. exustus and $S$. solidissima showed intermediary filtration rates. In $G$. demissa gill area increased with size at the same rate as filtration rate.
\end{abstract}

\section{INTRODUCTION}

In the intertidal zone of salt marshes, hard clams, oysters and ribbed mussels are important animals in the flow of energy and nutrients (Kuenzler 1961a,b, Jordan \& Valiela 1982). Furthermore, oysters, clams and scallops are commercially important, and aquaculture of these shellfish is a rapidly growing industry. When dealing with energy or nutrient budgets of suspension-feeding bivalves, the ingestion rate is of significant interest. The amount of food consumed by suspension-feeding bivalves is determined by the filtration rate and efficiency of particle retention by the gill which has evolved to act as both a water-transporting and a particle-retaining organ.

The bivalve gill consists of parallel oriented filaments possessing ciliary tracts. In addition to water-pumping lateral ciliary tracts and particle-transporting frontal ciliary tracts, the gill filaments passess laterofrontal ciliary tracts which may be composed of 2 types of ciliary structure: laterofrontal cirri and prolaterofrontal cilia (Owen \& McCrae 1976). The laterofrontal cirri are widely thought to act as filters and to retain particles from the water passing through the gill (Silvester \& Sleigh 1984).

Since the type of the laterofrontal tracts as well as the length of the laterofrontal cirri are suggested to be of particular significance in the retention of palicies, a comparative study of particle retention in bivalves with large, small and non-existent laterofrontal cirri forms part of the present study on filtration rates in 6 Northeast American bivalves.

\section{MATERIALS AND METHODS}

The experimental work was carried out at the Skidaway Institute of Oceanography, Georgia, USA, during July and August 1987.

Atlantic ribbed mussels Geukensia demissa (L.) and American oysters Crassostrea virginica (Gmelin) were collected from the intertidal zone in the vicinity of the institute. Northern quahogs (hard clam) Mercenaria mercenaria (L.) and scorched mussels Brachidontes exustus (L.) were collected at low tide in the salt marshes of the Wassaw Sound, an estuarine embayment in the Georgia Bight. Bay scallops Argopecten irradians (L.) came from St Joseph's Bay, Florida, USA. Atlantic surf clams Spisula solidissima (Dillwyn) originally came from National Marine Fisheries Services, Milford Laboratory, Connecticut, USA in 1986 and were planted in the salt marshes of the Wassaw Sound. In 